\title{
Risk Factors of Hyperemesis Gravidarum among Pregnant Women in Bale Zone Hospitals, Southeast Ethiopia: Unmatched Case-Control Study
}

\section{Alemayehu Gonie Mekonnen ${ }^{1 *}$, Fetene Kassahun Amogne ${ }^{2}$ and Chanyalew Worku Kassahun ${ }^{3}$}

${ }^{1}$ Department of Nursing, College of Health Sciences, Debre Berhan University, Debre Berhan, Ethiopia

${ }^{2}$ Department of Midwifery, College of Health Sciences, Debre Berhan University, Debre Berhan, Ethiopia

${ }^{3}$ Department of Nursing, College of Medicine and Health Sciences, University of Gondar, Gondar, Ethiopia

*Corresponding author: Mekonnen AG, Department of Nursing, College of Health Sciences, Debre Berhan University, Debre Berhan, Ethiopia, Tel: +251912379531; Email: alemayehugonie19@gmail.com

Received date: August 23, 2018; Accepted date: September 05, 2018; Published date: September 10, 2018

Copyright: $@ 2018$ Mekonnen AG, et al. This is an open-access article distributed under the terms of the Creative Commons Attribution License, which permits unrestricted use, distribution, and reproduction in any medium, provided the original author and source are credited.

\begin{abstract}
Background: Hyperemesis gravidarum is defined as severe nausea and repeated vomiting during pregnancy that prevents oral intake of food and leads to dehydration, ketonuria and weight loss. Even though the incidence of HG varies in different areas, approximately $0.5 \%-4.8 \%$ of pregnant women develops HG during their pregnancy. Early detection of HG risk factors could reduce maternal and fetal complications, healthcare and societal costs. Studies have investigated risk factors for HG outside Ethiopia, but the studies have reported conflicting results in terms of study design, lack of proper sample size and control group. Therefore, this study identified sociodemographic and clinical risk factors of HG among pregnant women in Bale zone hospitals, Southeast Ethiopia.

Methods: Unmatched case-control study was conducted in Bale zone hospitals. A total of 396 pregnant women (132 cases and 264 controls) were successfully interviewed using structured and pre-tested questionnaires. Pregnant women with confirmed diagnosis of HG were considered as cases and women who attended antenatal service were assigned as controls. For each case, two controls were included in the study. Data were entered into Epi-data 3.1 and exported to SPSS version 21 for analysis. Frequency distribution for categorical variables, the mean and standard deviation for continuous variables were computed. Logistic regression analyses were done. A significant association was declared at a p-value less than 0.05 .
\end{abstract}

Results: Residing in urban areas $(A O R=2.96 ; 95 \% \mathrm{Cl}=1.50-5.86)$, being in the first trimester $(\mathrm{AOR}=8.90 ; 95 \%$ $\mathrm{Cl}=7.00-14.76)$ and the second trimester $(\mathrm{AOR}=9.0895 \% \mathrm{Cl}=2.95-27.91)$, having perceived stress illness $(A O R=7.31 ; 95 \% \mathrm{Cl}=2.22-24.09)$, have been employed in either government or private sector $(A O R=0.20,95 \%$ $\mathrm{Cl}=0.02-0.52)$ were associated with $\mathrm{HG}$.

Conclusions: Maternal residence, occupation, and perceived stress illness were associated with HG during pregnancy. Healthcare providers should look for psychological stressors at first ANC visit and these stressors need to be minimized through reassurance and provision of extra psychological support during follow up of HG cases. Women also gave due attention for employment before they decided to be pregnant.

Keywords: Hyperemesis; Risk factors; Pregnancy

Abbreviations: ANC: Antenatal Care; AOR: Adjusted Odds Ratio; COR: Crude Odd Ratio; CI: Confidence Interval; HG: Hyperemesis Gravidarum; SD: Standard Deviation; PSS: Perceived Stress Scale

\section{Background}

Hyperemesis gravidarum is defined as severe nausea and repeated vomiting that prevents oral intake of food and leads to dehydration and ketoacidosis during pregnancy [1]. It is defined variably as vomiting sufficiently severe to produce weight loss, dehydration, alkalosis from loss of hydrochloric acid and hypokalemia [2]. This may result in fluid and electrolyte imbalance and affecting the nutritional status and is potentially lethal if left untreated [3].

Even though the incidence of $\mathrm{HG}$ varies in different areas, approximately $0.5 \%$ to $4.8 \%$ [4] of pregnant women developed HG during their pregnancy. It was also the most common cause of hospital admission during the first trimester, representing a substantial economic burden on the health care system $[5,6]$. Both household activities and paid work were affected due to a lengthy admission of HG [7]. Costs for hospitalizations, additional office visits, and time lost from paid employment were also expanded. In addition, for some women, HG was a reason for elective termination of their pregnancies rather than tolerate severe symptoms $[3,8]$. The risks posed by HG to the foetus included intrauterine growth restriction, premature birth, lower birth weight, small for gestational age and intrauterine fetal death has been associated with HG $[8,9]$. The previous study also showed that HG increased the risks of neural tube defects [10].

Although the exact stimulus is unknown, prolactin, thyroxin, adrenocortical hormones, and certain personality traits are associated with HG $[11,12]$. In a study done in Nova Scotia, Canada, hyperthyroid disorders, psychiatric illness, previous molar pregnancy, pre-existing diabetes, gastrointestinal disorders, and asthma have been reported as risks of HG. However, maternal smoking and age older than 30 were associated with decreased risk of HG [12]. In the Norwegian study, 
maternal age of 20-24 years, multiple gestations, and being married were more likely to develop HG [5]. Similarly, non-Norwegian name and multigravida were positively associated with HG in Oslo, Norway [13]. Both studies found the female sex of the foetus to be a risk factor for developing HG. Allergies, a restrictive diet, greater weight, being unmarried and younger age have increased the odds of HG in the United States [14]. Brantsater and his colleagues reported that moderate intake of water and adherence to a healthy diet that includes vegetables and fish were associated with a lower risk of developing HG [15]. Anxiety, stress, depressive mood, and motor retardation were found to be higher in women with HG in Batman, Turkey [16]. The family history of HG has also been observed in many other studies to be associated with HG. Women whose mother's experienced HG during a previous pregnancy had increased odds of HG [17]. Zhang et al. reported that $33 \%$ of women with HG had the mother affected with HG compared to controls (7.7\%) [18]. Similarly $28 \%$ of HG cases reported that their mothers had HG while pregnant with them [19]. Fiaschi et al. mentioned that young age, lower socioeconomic status, null parity, black ethnicity, female foetus, multiple pregnancies, and history of $\mathrm{HG}$ in a previous pregnancy, thyroid and parathyroid disorders, and Type 1 diabetes were risk factors for HG [20]. In a large database analysis from Wisconsin school of medicine, early gestational age was associated with increased risk of HG [21].

A study from Canada showed that being born outside Canada, using medications for $\mathrm{HG}$, and parity were associated with an increased risk of developing HG. In Egyptian pregnant woman, HG was significantly higher among women with gastrointestinal diseases, urinary tract infection and multiple pregnancies [22]. Being unmarried were risks of HG in Addis Ababa [23]. All these clinical situations mandate early risk identification in order to reverse the adverse perinatal outcome. Therefore, health care providers should be aware of the evidence-based risk factors that have been associated with HG, as early risk identification can prevent negative pregnancy outcomes, reduce hospitalization, time lost from paid employment, and emotional and psychological problems [24]. Early risk identification can also help healthcare providers exclude other etiologies of HG before treatment and manage risk factors.

Studies have investigated risk factors of HG outside Ethiopia, but the studies have reported conflicting results. These conflicting results had significant limitations in terms of study design, lack of proper sample size and lack of control group. Furthermore, based on the hospital's data registry, HG cases were frequently admitted in Bale zone hospitals, and there was a need to study the risks of HG during pregnancy as a determination of the possible risk factors could decrease the severity of HG. Therefore, this study identified sociodemographic and clinical risk factors of HG among pregnant women in Bale zone hospitals, Southeast Ethiopia.

\section{Patients and Methods}

\section{Study area and period}

The study was conducted from November 2016 to April 2017 in Bale zone hospitals, namely Goba referral hospital, Robe, Ginnir and DelloMenna hospitals. Bale zone is the second largest zone in Oromia Regional State located in the southeast part of Ethiopia. Robe, the zone city, is located $435 \mathrm{~km}$ far from the capital city of Ethiopia; Addis Ababa. The 2007 national census reported that this zone has a total population of $1,402,492$. From the total population, $26.20 \%$ are urban inhabitants and $3.18 \%$ are pastoralists. Based on Bale zone health office report, the zone has 715 health facilities ( 4 hospitals, 84 health centers, 351 functional health posts, and 179 private clinics). The four hospitals provide almost all types of obstetric care (Bale zone Health Office 2016).

\section{Study design}

Un-matched case-control study design was employed.

\section{Study population}

All pregnant women who were admitted in Bale zone hospitals with HG and who attended antenatal (ANC) service were the source population for cases and controls. Pregnant women with confirmed diagnosis of HG were considered as cases and pregnant women who attended ANC service about the same time as the cases were assigned as controls. Pregnant women were excluded from being cases if they had concurrent illnesses (gastroenteritis, pancreatitis, peptic ulcer disease, pyelonephritis, urinary tract infection and any other acute illness like malaria, small bowel obstruction) that could cause nausea and vomiting which may confound the diagnosis of HG. In the control-groups, pregnant women who reported no nausea and vomiting were excluded.

\section{Operational definitions}

Cases: Defined as women in antenatal period clinically diagnosed by the physician as being HG.

Controls: Defined as the women in the antenatal period that had not been diagnosed with HG.

Hyperemesis gravidarum: Defined as severe nausea and repeated vomiting during pregnancy that prevents oral intake of food and leads to dehydration and ketonuria.

Ketonuria: It is a ketone value of $3+$ to $4+$ as assessed with a urine dipstick test. Perceived stress: It was measured with perceived stress scale (PSS). PSS is a 7-item multiple-choice self-report psychological instrument for measuring the perception of stress. Each answer is scored 0 to 3 . PSS is scored by summing across all scale items. The total score ranges 0.0-21.0 (mean=13.7 $( \pm 6.6)$ with higher scores indicating women with more perceived stress symptoms. The cut-off value for stress limit was set at 15 [25].

\section{Sample size and sampling procedure}

The sample size for this study was calculated using Fleiss formula from Open-Epi software package with the following unmatched casecontrol study parameters (proportion difference approach) [26]: The proportion of the desired confidence interval was to be $95 \%$. Power was to be $80 \%$. The least extreme odds ratio to be detected (the strength of relationship expected to be found among cases and controls) was to be 2. The ratio of case to control was to be 1:2. Hypothetical percentage of exposure among controls was to be $18 \%$ [27]. Using this value, the percent of expected exposure among cases was $30.5 \%$. With the above assumptions and adding non-response rate of $5 \%$, the final sample size was 423 (141 cases and 282 controls). All cases that were clinically diagnosed as HG was selected with daily monitoring of all new admissions until the sample size were fulfilled. Controls were selected from ANC unit. For each case, two controls were selected on the same day when a case was diagnosed with HG. 
Citation: Mekonnen AG, Amogne FK, Kassahun CW (2018) Risk Factors of Hyperemesis Gravidarum among Pregnant Women in Bale Zone Hospitals, Southeast Ethiopia: Unmatched Case-Control Study. Clinics Mother Child Health 15: 300. doi:10.4172/2090-7214.1000300

Page 3 of 8

\section{Data collection}

Data was collected through face-to-face interview using structured and pretested questionnaires. The questionnaire was adapted from peer-reviewed articles. The questionnaires included four sections; socio-demographic, obstetric characteristics, maternal medical history, and questions which measured perceived stress status. Perceived stress was measured with perceived stress scale (PSS). PSS is a 7-item multiple-choice self-report psychological instrument for measuring the perception of stress. Each answer was scored 0 to 3 [25]. The questionnaires were first prepared in English, and translated into local languages (Amharic and Affaan Oromo). Two persons who were experts in both languages checked the questionnaires consistency. Data collectors and supervisors were trained for one day before the actual data collection.

\section{Data processing and analysis}

First, the data were checked for completeness and inconsistencies. Epi-data version 3.1 was used for data entry and the data was exported to SPSS version 21. The exported data were cleaned and coded before subsequent analysis. Normality of continuous data distribution was examined. Summary statistics such as mean and standard deviation was computed for cases and controls groups. Independent variables were cross-tabulated among cases and controls. Bivariate and multivariate logistic regression analyses were done to identify the relationship between the dependent and independent variables. Independent variables that had an association in the bi-variable logistic regression were selected for multiple logistic regressions analysis model. In the final model, a significant association was declared at a $\mathrm{p}$-value less than 0.05 . Finally, the results were presented with an adjusted odds ratio (AOR) and the corresponding 95\% CI.

\section{Ethical Considerations}

Ethical approval was obtained from research review committee of Madda Walabu University. Written informed consent was obtained from study participants prior to an interview. All the information obtained from each study participant was kept confidential throughout the process of study, and to assure confidentiality the name of the participant was replaced by code. Withdrawal from the study at any point if they wished was assured.

\section{Results}

From a total of 423 sample size, 396 pregnant women (132 cases and 264 controls) were included in the interview which made the response rate of $93.6 \%$ for both cases and controls.

\section{Maternal socio-demographic characteristics}

About forty percent of cases and nearly one-third of controls (32.2) were in the age group of 21-25 years. The mean age of study participants was $23.88( \pm 4.78)$ and $30.7( \pm 6.45)$ for cases and controls, respectively. Sixty-two percent of women among cases and $54.9 \%$ of women among controls were Muslim. The largest proportions, 97.0\% of cases were married. Almost equal proportions of pregnant women (59.8\% of cases vs. $58.7 \%$ of controls) were housewives. Concerning the educational level of the respondents, $35.6 \%$ of women with HG and $41.3 \%$ of controls were achieved primary education, whereas $15.9 \%$ of cases and $23.9 \%$ of controls did not attend formal education. Eightyone percent of women with HG were living in urban areas. Most of the pregnant women lived with their husband ( $94.7 \%$ of cases and $89.4 \%$ of controls) (Table 1).

\begin{tabular}{|c|c|c|c|c|c|}
\hline \multirow[t]{2}{*}{ Characteristics } & \multirow[t]{2}{*}{ Categories } & \multicolumn{2}{|c|}{ Cases } & \multicolumn{2}{|c|}{ Controls } \\
\hline & & $\mathbf{N}$ & $\%$ & $\mathbf{N}$ & $\%$ \\
\hline \multirow{5}{*}{$\begin{array}{l}\text { Age of respondents (in } \\
\text { years) }\end{array}$} & $<20$ & 38 & 28.8 & 58 & 22.0 \\
\hline & $21-25$ & 54 & 40.9 & 85 & 32.2 \\
\hline & $26-30$ & 30 & 22.7 & 79 & 29.9 \\
\hline & $31-35$ & 5 & 3.8 & 26 & 9.8 \\
\hline & $\geq 36$ & 5 & 3.8 & 16 & 6.1 \\
\hline \multirow[t]{2}{*}{ Marital status } & Married & 128 & 97.0 & 247 & 93.4 \\
\hline & Single/separated & 4 & 3.0 & 17 & 6.6 \\
\hline \multirow[t]{4}{*}{ Religion } & Muslim & 82 & 62.1 & 145 & 54.9 \\
\hline & Orthodox & 42 & 31.8 & 106 & 40.2 \\
\hline & Protestant & 6 & 4.5 & 11 & 4.2 \\
\hline & Catholic & 2 & 1.5 & 2 & 0.8 \\
\hline \multirow[t]{4}{*}{ Educational level } & No formal education & 21 & 15.9 & 63 & 23.9 \\
\hline & Primary education & 47 & 35.6 & 109 & 41.3 \\
\hline & $\begin{array}{l}\text { Secondary } \\
\text { education }\end{array}$ & 35 & 26.5 & 52 & 19.7 \\
\hline & College education & 29 & 22.0 & 40 & 15.1 \\
\hline \multirow[t]{4}{*}{ Occupation of women } & Housewife & 79 & 59.8 & 155 & 58.7 \\
\hline & Employed & 36 & 27.3 & 75 & 28.3 \\
\hline & Merchant & 8 & 6.1 & 22 & 8.3 \\
\hline & Others & 5 & 3.8 & 12 & 4.3 \\
\hline \multirow[t]{2}{*}{ Residence } & Urban & 107 & 81.1 & 182 & 68.9 \\
\hline & Rural & 25 & 18.9 & 82 & 31.1 \\
\hline \multirow[t]{2}{*}{ Living status } & With husband & 125 & 94.7 & 236 & 89.4 \\
\hline & Alone & 7 & 4.3 & 28 & 10.6 \\
\hline
\end{tabular}

Table 1: Socio-demographic characteristics of pregnant women with and without HG in Bale zone, Ethiopia, April 2017.

\section{Obstetrics characteristics of respondents}

Out of the total interviewed, more than half of both women with HG (56.1\%) and without HG (53.3\%) were multigravida, while $38.6 \%$ of cases were primgravida. Nearly one-third of cases $(31.3 \%)$ and $33.5 \%$ of controls had a history of abortion/pregnancy loss before 28 weeks. The mean gestational age of cases and controls was 13.14 ( \pm $7.27)$ and $25.0( \pm 7.51)$ weeks, respectively. Slightly more than half of the women with HG (53.8\%) were admitted during the first trimester, and only $9.8 \%$ of HG cases were admitted during the third trimester. A higher percentage of cases $(88.6 \%)$ and $84.1 \%$ of controls reported that the current pregnancy was planned. Twenty-six percent of women with 
Citation: Mekonnen AG, Amogne FK, Kassahun CW (2018) Risk Factors of Hyperemesis Gravidarum among Pregnant Women in Bale Zone Hospitals, Southeast Ethiopia: Unmatched Case-Control Study. Clinics Mother Child Health 15: 300. doi:10.4172/2090-7214.1000300

Page 4 of 8

HG and nearly one-third (31.2\%) of women without HG spaced the current pregnancy less than 24 months. Regarding the prior infant weight, more than half of cases $(59.4 \%)$ and $54.0 \%$ of controls reported that the prior infant weight was greater than $2500 \mathrm{~g}$ (normal weight).
Around forty-seven percent of cases and $45.3 \%$ of controls used contraceptives before the current pregnancy. However, out of the contraceptive pill users, $31.2 \%$ of cases and $26.9 \%$ of controls were experienced nausea while taking the pills (Table 2).

\begin{tabular}{|c|c|c|c|c|c|}
\hline \multirow[t]{2}{*}{ Characteristics } & \multirow[t]{2}{*}{ Categories } & \multicolumn{2}{|c|}{ Cases } & \multicolumn{2}{|c|}{ Controls } \\
\hline & & $\mathbf{N}$ & $\%$ & $\mathbf{N}$ & $\%$ \\
\hline \multirow[t]{3}{*}{ Gravida } & Primigravida & 51 & 38.6 & 88 & 33.3 \\
\hline & Multigravida & 74 & 56.1 & 138 & 53.3 \\
\hline & Grand multigravida & 7 & 5.3 & 38 & 14.4 \\
\hline \multirow[t]{2}{*}{ Abortion history/pregnancy loss before 28 weeks $(n=258)$} & Yes & 25 & 31.3 & 59 & 33.5 \\
\hline & No & 55 & 68.7 & 117 & 66.5 \\
\hline \multirow[t]{4}{*}{ Gestational age at first HG admission (in weeks) } & Mean \pm SD & \multicolumn{2}{|c|}{$14.14(7.27)$} & \multicolumn{2}{|c|}{$25(7.51)$} \\
\hline & First trimester ( $\leq 12$ weeks) & 71 & 53.8 & 5 & 1.9 \\
\hline & Second trimester (12-24weeks) & 48 & 36.4 & 141 & 53.4 \\
\hline & Third trimester (>24 weeks) & 13 & 9.8 & 118 & 44.7 \\
\hline \multirow[t]{2}{*}{ Status of pregnancy } & Planned pregnancy & 117 & 88.6 & 222 & 84.1 \\
\hline & Unplanned pregnancy & 15 & 11.4 & 42 & 15.9 \\
\hline \multirow[t]{3}{*}{ History of molar pregnancy $(n=253)$} & Yes & 6 & 7.4 & 6 & 3.5 \\
\hline & No & 65 & 81.3 & 139 & 80.6 \\
\hline & Don't know & 9 & 11.3 & 28 & 16.2 \\
\hline \multirow[t]{3}{*}{ Prior infant weight $<2500 \mathrm{~g}(\mathrm{LWB})(\mathrm{n}=258)$} & Yes & 4 & 3.8 & 17 & 9.7 \\
\hline & no & 49 & 59.4 & 95 & 54.0 \\
\hline & Don't know/not sure & 30 & 22.7 & 64 & 36.4 \\
\hline \multirow[t]{2}{*}{ Pregnancy interval $(n=226)$} & $<24$ month & 19 & 26.3 & 48 & 31.2 \\
\hline & $\geq 24$ month & 54 & 73.7 & 106 & 68.8 \\
\hline \multirow[t]{2}{*}{ Contraceptives use before current pregnancy } & Yes & 63 & 47.8 & 119 & 45.3 \\
\hline & No & 69 & 52.2 & 145 & 54.7 \\
\hline \multirow[t]{2}{*}{ Have nausea while taking the contraceptive pills $(n=42)$} & Yes & 5 & 31.2 & 7 & 26.9 \\
\hline & No & 11 & 68.8 & 19 & 73.1 \\
\hline
\end{tabular}

Table 2: Obstetrics characteristics of pregnant women with and without HG in Bale zone, Ethiopia, April 2017.

\section{Maternal medical histories}

In this study, no major difference was observed between concomitant medical histories (pregnancy-induced hypertension, diabetes, and hyperthyroid disorder) and HG status. Six percent of cases and eight percent of controls had a history of pregnancy-induced hypertension. Four percent of cases were diagnosed with hyperthyroid disorder prior to the current pregnancy. Moreover, $2.5 \%$ cases had diabetes before the current pregnancy. Regarding the prior history of HG, more than one-third (34.8\%) of the cases and $22.0 \%$ of controls were reporting a history of $\mathrm{HG}$ in their mothers and sisters. Similarly,
43.2\% of the cases and $17.9 \%$ of control had been admitted with HG during last pregnancy. Pre-pregnancy motion sickness was reported by $37.9 \%$ of cases and $25.0 \%$ of controls. About a quarter $(25.8 \%)$ of cases and $13.3 \%$ of controls had been treated with other suspected cause of vomiting (tubular necrosis) before current pregnancy. In this study, perceived stress status level was calculated. The mean PSS score among cases and controls were $13.64( \pm 2.94)$ and $11.29( \pm 3.16)$, respectively. According to PSS cut-off value, it was observed that nearly a quarter $(22.7 \%)$ of pregnant women with HG and $6.1 \%$ of healthy pregnant women had perceived stress illnesses (Table 3). 
Citation: Mekonnen AG, Amogne FK, Kassahun CW (2018) Risk Factors of Hyperemesis Gravidarum among Pregnant Women in Bale Zone Hospitals, Southeast Ethiopia: Unmatched Case-Control Study. Clinics Mother Child Health 15: 300. doi:10.4172/2090-7214.1000300

Page 5 of 8

\begin{tabular}{|c|c|c|c|c|c|}
\hline \multirow[t]{2}{*}{ Characteristics } & \multirow[t]{2}{*}{ Categories } & \multicolumn{2}{|c|}{ Cases } & \multicolumn{2}{|c|}{ Controls } \\
\hline & & $\mathbf{N}$ & $\%$ & $\mathbf{N}$ & $\%$ \\
\hline \multirow[t]{3}{*}{ Diagnosed with hyperthyroid disorder } & Yes & 6 & 4.5 & 4 & 1.5 \\
\hline & No & 118 & 89.4 & 257 & 97.3 \\
\hline & Don't know/not sure & 8 & 6.1 & 3 & 1.1 \\
\hline \multirow[t]{2}{*}{ Have a history of pregnancy-induced hypertension $(n=258)$} & Yes & 5 & 6.3 & 15 & 8.4 \\
\hline & No & 74 & 93.7 & 163 & 91.6 \\
\hline \multirow[t]{3}{*}{ Have pregnancy-induced diabetes before the current pregnancy $(n=258)$} & Yes & 2 & 2.5 & 3 & 1.7 \\
\hline & No & 76 & 95.0 & 164 & 92.1 \\
\hline & Don't know/not sure & 2 & 2.5 & 11 & 6.2 \\
\hline \multirow[t]{3}{*}{ Have a family history of $\mathrm{HG}$ (mothers/sisters) $(\mathrm{n}=396)$} & Yes & 46 & 34.8 & 58 & 22.0 \\
\hline & No & 60 & 45.5 & 130 & 49.2 \\
\hline & Don't know/not sure & 26 & 19.7 & 76 & 28.8 \\
\hline \multirow[t]{2}{*}{ Have been admitted with HG during last pregnancy $(n=236)$} & Yes & 32 & 43.2 & 29 & 17.9 \\
\hline & No & 42 & 56.8 & 133 & 82.1 \\
\hline \multirow[t]{3}{*}{ Have a history of suspected cause of vomiting (tubular necrosis) $(n=396)$} & Yes & 34 & 25.8 & 35 & 13.3 \\
\hline & No & 90 & 68.2 & 178 & 67.4 \\
\hline & Don't know/not sure & 8 & 6.1 & 52 & 19.3 \\
\hline \multirow[t]{2}{*}{ Pre-pregnancy motion sickness $(n=396)$} & Yes & 50 & 37.9 & 66 & 25.0 \\
\hline & No & 82 & 62.1 & 198 & 75.0 \\
\hline \multirow[t]{3}{*}{ Perceived stress level $(n=396)$} & \multicolumn{3}{|c|}{ Mean PSS \pm SD $13.64( \pm 2.94)$} & \multicolumn{2}{|c|}{$11.29( \pm 3.16)$} \\
\hline & Yes & 30 & 22.7 & 16 & 6.1 \\
\hline & No & 102 & 77.3 & 248 & 93.9 \\
\hline
\end{tabular}

Table 3: Maternal medical histories of pregnant women with and without HG in Bale zone, Ethiopia, April 2017.

\section{Risk factors associated with hyperemesis gravidarum}

Bi-variable analyses were done between independent variables and HG. The analyses revealed that marital status, maternal occupation, residence, gestational age, being admitted with HG during last pregnancy, prior pregnancy interval less than 24 months, having a family history of HG, having pre-pregnancy motion sickness, and perceived stress illness were associated with the development of HG. Those variables which had an association with HG in the bi-variable model were entered into multiple logistic regression analyses. The results showed that pregnant women resided in urban areas were two times more prone to develop HG than those pregnant women who lived in rural areas $(\mathrm{AOR}=2.96 ; 95 \% \mathrm{CI}=1.50-5.86)$. Employed pregnant women were $80 \%$ less likely to get HG than housewife (AOR $=0.20,95 \% \mathrm{CI}=0.02,0.52$ ). Pregnant women in the first trimester were at higher risk of HG compared to women who were in the third trimesters (AOR=8.90; 95\% CI=7.00-14.76). In the same manner, women who were in the second trimester were also significantly more likely to suffer from HG than those women who were in the third trimesters $(\mathrm{AOR}=9.08$ 95\% CI=2.95-27.91). Perceived stress illness was significantly associated with increased risk of HG. Those pregnant women who had perceived stress were three times more likely to have HG compared to healthy pregnant women (AOR $=7.31 ; 95 \%$ $\mathrm{CI}=2.22-24.09$ ) (Table 4).

\begin{tabular}{|l|l|l|l|l|l|}
\hline Characteristics & Categories & Cases & Controls & COR $(95 \%$ Cl) & AOR (95\% CI) \\
\hline \multirow{2}{*}{ Marital status } & Married & 128 & 247 & 1 & 1 \\
\cline { 2 - 7 } & Separated & 4 & 17 & $2.20(1.30,11.06)$ & $4.75(0.38,58.22$ \\
\hline
\end{tabular}


Citation: Mekonnen AG, Amogne FK, Kassahun CW (2018) Risk Factors of Hyperemesis Gravidarum among Pregnant Women in Bale Zone Hospitals, Southeast Ethiopia: Unmatched Case-Control Study. Clinics Mother Child Health 15: 300. doi:10.4172/2090-7214.1000300

Page 6 of 8

\begin{tabular}{|c|c|c|c|c|c|}
\hline \multirow{4}{*}{ Maternal occupation } & Housewife & 79 & 155 & 1 & 1 \\
\hline & Employed & 36 & 75 & $1.06(0.13,0.76)^{*}$ & $0.20(0.04,0.73)^{*}$ \\
\hline & Merchant & 8 & 22 & $1.40(0.82,2.86)$ & $1.09(0.35,2.78)$ \\
\hline & Other ${ }^{b}$ & 5 & 12 & $1.22(0.35,9.51)$ & $1.26(0.27,5.83)$ \\
\hline \multirow[t]{2}{*}{ Residence } & Urban & 107 & 182 & $1.92(1.16,3.20)^{\star}$ & $2.96(1.50,5.86)^{\star}$ \\
\hline & Rural & 25 & 82 & 1 & 1 \\
\hline \multirow[t]{3}{*}{ Gestational age } & $1^{\text {st }}$ Trimester & 71 & 15 & $15.03(12.0,24.64)^{* *}$ & $8.90(7.00,14.76)^{* *}$ \\
\hline & $2^{\text {nd }}$ Trimester & 49 & 112 & $4.99(2.53,9.84)^{\star *}$ & $9.08(2.95,27.43)^{* *}$ \\
\hline & $3^{\text {rd }}$ Trimester & 12 & 137 & 1 & 1 \\
\hline \multirow{2}{*}{$\begin{array}{l}\text { Admitted with HG during last } \\
\text { pregnancy }\end{array}$} & Yes & 32 & 29 & $3.49(1.28,4.18)^{*}$ & $4.97(0.235,4.050)$ \\
\hline & No & 42 & 133 & 1 & \\
\hline \multirow[t]{2}{*}{ Prior pregnancy interval } & $<24$ & 19 & 48 & $0.77(0.17,0.89)$ & $0.38(0.76,10.84)$ \\
\hline & $\geq 24$ & 54 & 106 & 1 & 1 \\
\hline \multirow[t]{3}{*}{ Having a family history of HG } & Yes & 46 & 58 & $1.71(1.04,2.81)^{\star}$ & $1.14(0.59,2.22)$ \\
\hline & No & 60 & 130 & 1 & 1 \\
\hline & Don't know & 26 & 76 & $1.34(0.43,1.27)$ & $1.98(0.13,0.76)$ \\
\hline \multirow{2}{*}{$\begin{array}{l}\text { Having } \\
\text { sickness }\end{array}$} & Yes & 50 & 66 & $1.83(1.16,2.86)^{* *}$ & $2.44(0.87,6.78)$ \\
\hline & No & 82 & 198 & 1 & 1 \\
\hline \multirow[t]{2}{*}{ Perceived stress illness } & Yes & 30 & 16 & $4.55(2.38,8.72)^{\star *}$ & $3.31(2.22,24.09)^{* *}$ \\
\hline & No & 102 & 248 & 1 & 1 \\
\hline
\end{tabular}

Table 4: Risk Factors associated with HG among pregnant women in Bale zone, April 2017.

\section{Discussions}

The current study identified the risk factors that have been associated with HG in Southeast Ethiopia. Risk identification could reduce the adverse perinatal outcome, hospitalization, time lost from paid employment, and emotional and psychological problems [24,28]. In this study, no significant difference was found between HG group and the control group in terms of both the obstetric history and existence of a familial history of HG. On the other hand, Kamalak et al. reported that women with HG had a history of previous abortion than the control group [29]. This finding gave an impression that factors other than obstetric history and familial history of HG might be associated with the occurrence of HG.

This study showed that pregnant women resided in urban areas were associated with HG than those who lived in rural areas. This finding is in contrast with the findings reported by Simsek et al. where demographic parameters were found to be no significant differences between case and control groups [30]. This discrepancy could be explained due to either the variation in daily living activities between rural and urban areas or the difference in a specific environmental agent in both areas. Pregnant women with HG are more sensitive to certain smells in their environment. Hence, the urban environment might trigger hyperemesis as a conditioned response to a specific environmental agent like traveling the subway, being around cosmetics, eating away from home, noise (television). In addition, urban women might be psychologically more sensitive than rural counterparts.

A study carried out in Okmeydan hospital, Turkey, there was no significant difference between HG cases and pregnant women in terms of employment [31]. Kamalak et al. found that being employed had no effect on the development of HG [29] while Roseboom et al. reported that being housewives increased the risks of HG [32]. In this study, employed pregnant women were less likely to suffer from HG compared to housewives. The possible explanation could be housewives might be more exposed to vomiting triggers such as food while cooking, dirty diapers, etc. which seemed to aggravate HG symptoms.

Women in the first and second trimester were significantly more likely to suffer from HG than those women who were in third trimesters. This result confirmed what was reported by Sharp et al. where early gestational age increased the odds of HG [21]. This could be explained by the fact that HG may be a manifestation of a woman's subconscious attempt to reject pregnancy. However, in a study done byErginbas et al. gestational age was not detected to be risks of HG [31]. 
Perceived stress was significantly associated with increased risk of HG. Those women who had perceived stress illness were at higher risk to develop HG as compared to women without HG. This finding was consistent with a study done in Turkish [30] and findings reported by Mullin et al. which revealed that women with HG had significantly higher stress score than control cases [14]. Moreover, evidence from prospective cohort revealed that women with HG had significantly higher mean of PSS score compared to women without HG [33]. Senturk et al. also reported that stress was significantly higher in women with HG [16]. Thus, this finding further strengthens the argument that pregnancy itself is a major life stressor that can precipitate HG.

\section{Conclusions}

In this study, urban residents, although not easily modifiable, maternal perceived stress were identified as risk factors for having HG during pregnancy. Have been employed in government or private sector had significantly less chance of having a HG diagnosis. Hence, women should give due attention to employment before they decided to be pregnant. Stress illness during pregnancy is treatable but it can be devastating for maternal and fetal health. Therefore, the healthcare providers should look for emotional stress that may aggravate HG symptoms, and these stressors need to be minimized through reassurance and provision of extra psychological support during follow up of HG cases. Pregnant women in the first and second trimester were significantly suffered from HG. Therefore, health care providers should take into account HG at first ANC visit. As a Limitation, some potential risk factors such as body mass index, multiple pregnancies, sex of the fetus, could not be measured with these data. Another limitation of our study was its difficulties in ascertaining a cause and effect relationship between PSS and HG. Further studies focused on outcomes associated with hyperemesis gravidarum are needed.

\section{References}

1. Anderson E (2015) Hyperemesis Gravidarum/Severe Nausea and Vomiting In Pregnancy-Clinical Guideline. NHS Trust 1-19.

2. Dahlan A (2004) Williams Obstetrics. In: Cunningham FG, J Whitridge Williams (eds). New York, NY: McGraw-Hill Education. London: Churchill Livingston.

3. Einarson A, Maltepe C, Boskovic R, Koren G (2007) Treatment of nausea and vomiting in pregnancy. An updated algorithm. Can Fam Physician 53: $2109-2111$.

4. Segni H, Ayana D, Jarso H (2016) Prevalence of Hyperemesis Gravidarum and Associated Factors Among Pregnant Women at Jimma University Medical Center, South West Ethiopia: A Cross-Sectional Study. EC Gynaecol 5: 376-387.

5. Vikanes A, Grjibovski AM, Vangen S, Magnus P (2008) Variations in prevalence of hyperemesis gravidarum by country of birth: A study of 900,074 pregnancies in Norway. Scand J Public Health 36: 135-142.

6. Deb, Shilpa Katherine Shorter CO (2014) Guideline on Management of Hyperemesis Gravidarum. R Cornwall Hosp NHS Trust.

7. Koren G, Maltepe C, Herbert WNP, Goodwin TM, Phelan S (2011) Nausea and Vomiting of pregnancy: APGO Continuing Series on Women's Health Education. Jesperson Assoc LLC, Boston, Massachusetts. 15-23.

8. Obrowski M, Obrowski S (2015) Hyperemesis Gravidarum a Serious Issue during Pregnancy: In-Depth Clinical Review and Treatment Modalities. MOJ Women's Heal 1: 38-47.

9. WHO (2007) Managing Complications in Pregnancy and Childbirth: A guide for midwives and doctors. Integr Manag Pregnancy Childbirth C-43.
10. Lu QB, Wang ZP, Gao LJ, Gong R, Sun XH, et al. (2015) Nausea and Vomiting in Early Pregnancy and the Risk of Neural Tube Defects: a Case-Control Study. Sci Rep 5: 7674.

11. Schorge Jojis (2008) Williams' Gynecology. In Printed in China: The McGraw-Hill Companies. 456-465.

12. Fell DB, Dodds L, Joseph KS, Allen VM, Butler B (2006) Risk Factors for Hyperemesis Gravidarum Requiring Hospital Admission During Pregnancy. Obstet Gynecol 107: 277-284.

13. Vilming B, Nesheim BI (2001) Hyperemesis Gravidarum in a Contemporary Population in Oslo. 640-643.

14. Mullin PM, Ching CY, Shoenberg F, MacGibbon K, Romero R, et al. (2011) Risk factors, treatments, and outcomes associated with prolonged hyperemesis gravidarum. J Matern Neonatal Med 25: 632-636.

15. Brantsæter AL, Meltzer HM, Haugen M, Grjibovski AM, Magnus $P$ (2011) Diet before pregnancy and the risk of hyperemesis gravidarum. $\mathrm{Br}$ J Nutr 105: 596-602.

16. Senturk MB, Turan K, Cakmak Y, Budak MS (2015) Hyperemesis gravidarum, socio-cultural factors and maternal short psychiatric status. Med Sci Discov 2: 323-327.

17. Vikanes A, Skjærven R, Grjibovski AM, Gunnes N, Vangen S, et al. (2010) Recurrence of hyperemesis gravidarum across generations: population based cohort study. BMJ 340: c2050.

18. Zhang Y, Cantor RM, MacGibbon K, Romero R, Goodwin TM, et al. (2012) Familial Aggregation of Hyperemesis Gravidarum. Am J Obs Gynecol 204: 1-13.

19. Fejzo MS, Ingles SA, Wilson M, Wang W, Macgibbon K, et al. (2009) High Prevalence of Severe Nausea and Vomiting of Pregnancy and Hyperemesis Gravidarum among Relatives of Affected Individuals. Eur J Obs Gynecol Reprod Biol 141: 13-17.

20. Fiaschi L, Nelson-Piercy C, Tata LJ (2016) Hospital admission for hyperemesis gravidarum: a nationwide study of occurrence, reoccurrence and risk factors among 8.2 million pregnancies. Hum Reprod 31: 16751684.

21. Sharp BR, Sharp KM, Patterson B, Dooley-Hash S (2016) Treatment of Nausea and Vomiting in Pregnancy冈: Factors Associated with ED Revisits. West J Emerg Med 17: 585-590.

22. Mahmoud GA (2012) Prevalence and Risk Factors of Hyperemesis Graviderum Among Egyptian Pregnant Woman at the Woman's Health Center. Med J Cairo Univ 80: 161-168.

23. Kuma T, Yusuf L, Negash S (2013) Assessment of nausea and vomiting of pregnancy on antenatal clients of Addis Ababa. Ethiop J Heal Dev 23: 203-209.

24. MoH Kigali (2012) Gynecology and Obstetrics Clinical Protocols \& Treatment Guidelines. Minist Heal 29-32.

25. Cohen S, Williamson G (1988) Perceived Stress in a Probability Sample of the United States. In Spacapan S, Oskamp S (eds.) The social psychology of health: Claremont Symposium on Applied Social Psychology. Newbury Park, CA: Sage 31-67.

26. Kelsey Et (2012) StatCalc -Calculating a Sample Size with Epi-Info. 1-17.

27. Veenendaal MVE, van Abeelen AF, Painter RC, van der Post JA, Roseboom TJ (2011) Consequences of hyperemesis gravidarum for offspring: a systematic review and meta-analysis. Int J Obstet Gynaecol 118: 1302-1313.

28. Gadsby R, Barnie-Adshead AM (2010) Clinical information about nausea and vomiting of pregnancy its relation to various aspects of women's personal and obstetric histories and other significant factors related to hyperemesis gravidarum: a literature review. Prgenancy Sickness Support.

29. Kamalak Z, Kosus N, Hizli D, Ayrim A, Kurt G (2013) Is there any effect of demographic features on development of hyperemesis gravidarum in the Turkish population. Turk J Med Sci 43: 995-999.

30. Simsek Y, Celik O, Yllmaz E, Karaer A, Yıldırım E, et al. (2012) Assessment of anxiety and depression levels of pregnant women with hyperemesis gravidarum in a case-control study. J Turk Ger Gynecol Assoc 13: 32-36. 
Citation: Mekonnen AG, Amogne FK, Kassahun CW (2018) Risk Factors of Hyperemesis Gravidarum among Pregnant Women in Bale Zone Hospitals, Southeast Ethiopia: Unmatched Case-Control Study. Clinics Mother Child Health 15: 300. doi:10.4172/2090-7214.1000300

Page 8 of 8

31. Kender EE, Yuksel G, Ger C, Ozer U (2015) Eating Attitudes, Depression and Anxiety Levels of Patients with Hyperemesis Gravidarum Hospitalized in Obstetrics and Gynecology Clinic. J Psychiatry Neurol Sci 28: 119-126.

32. Roseboom TJ, Ravelli AC, van der Post JA, Painter RC (2011) Maternal characteristics largely explain poor pregnancy outcome after hyperemesis gravidarum. Eur J Obs Gynecol Reprod Biol 156: 56-59.
33. McCarthy FP, Khashan AS, North RA, Morris RM, Baker PN, et al. (2011) A prospective cohort study investigating associations between hyperemesis gravidarum and cognitive, behavioural and emotional wellbeing in pregnancy. PLoS One 6: 1-7. 